\title{
AUTONOMÍAS CONSTITUCIONALES E INSTITUCIONES CONTRAMAYORITARIAS (A PROPÓSITO DE LAS APORÍAS DE LA “DEMOCRACIA CONSTITUCIONAL")***
}

\begin{abstract}
RESUMEN
El artículo analiza el concepto de autonomía constitucional y las entidades dotadas de autonomía en la organización básica del Estado. En especial aborda la autonomía como concepto que permite explicar el locus de entidades como el Tribunal Constitucional, Banco Central, Contraloría General de la República, orientadas a guardar un cierto orden de la Constitución, y en tal medida despliegan toda su fuerza como instituciones contramayoritarias.
\end{abstract}

\section{PALABRAS CLAVES}

Autonomía constitucional territorial y funcional, instituciones contramayoritarias, controles y responsabilidades, democracia constitucional.

\footnotetext{
ABSTRACT

This paper analyses the concept of "constitutional autonomy" and the entithys with autonomy in the organization basic of State (Government ). An specialy

* Artículo recibido con fecha 2 de mayo de 2007 y aceptada su publicación el 10 de junio.

** Ponencia a Congreso "100 Años de la Ley de Habitaciones Obreras: Pasado, Presente y Futuro del Derecho Laboral, de la Seguridad Social y de los Derechos Económicos, Sociales y Culturales"; Facultad de Derecho, Universidad de Chile, 2 a 5 de octubre de 2006. Versión completa. Una versión abreviada se publica en la Revista de Derecho del Consejo de Defensa del Estado.

*** Profesor de Derecho Constitucional, Universidad Diego Portales. E-mail: zdc@zdcabogados.cl.
} 
abord the autonomy as concept facility the "locus" the entithys as the Constitutional Court, Central Bank, Accountatility General of Republic, the finish is guard an order the Constitution, and in the force as contramayoritarian institutions

\section{KEY WORDS}

Constitutional autonomy territorial and funcional, contramayoritarian institutions, constitutional democracy.

\section{I.- Prolegómenos.}

La autonomía es un concepto que opera tanto en el Estado como en la sociedad civil, y tiene antecedentes medievales en concordancia con la diversidad organizacional del orden feudal y estamental, aunque sus raíces modernas son: la teoría del "pouvoir" municipal de la Constituyente francesa y belga, la teoría de la descentralización dirigida contra la centralización napoleónica, la teoría de la corporación como instrumento para refrenar a la burocracia y la teoría del "self government" (Stern). Incluso más la autonomía opera como principio basal, en la construcción kantiana de los derechos fundamentales, de naturaleza individual o civil (Friedrich). Ello significa que la autonomía no existe como concepto "axiomático o apriorístico", tiene que ser expuesto con una institución concreta $(\text { Stern })^{1}$.

Contemporáneamente, y superando la desconfianza del viejo liberalismo burgués revolucionario hacia las asociaciones, gremios, corporaciones y vinculaciones en general concernientes a la propiedad, el trabajo y las profesiones, tanto a partir del barón de Montesquieu como de Tocqueville el constitucionalismo liberal admite el pluralismo social expresado en cuerpos intermedios de la sociedad civil y la autonomía de éstos para cumplir sus fines y funciones específicas. ${ }^{2} \mathrm{Al}$ mismo tiempo el viejo dogma-principio de la separación de poderes (en su dimensión horizontal y vertical) que está en la arquitectura del Estado, conservando su finalidad política con miras al equilibrio y limitación del poder público, es sustituido por un más técnico principio de distribución funcional del poder político estatal, principio que da cuenta del crecimiento del Estado, en la transición del Estado Liberal al Estado Benefactor, y por tanto, de la complejidad del Estado mismo sometido a procesos de socializaciónestatalización.

Stern, Klaus: "Derecho del Estado de la República Federal Alemana” (trad. J. Pérez Royo y P. Cruz Villalón) Edit CEC, Madrid, 1987, pág. 690 y ss. De Carl J. Friedrich "Gobierno Constitucional y Democracia. Teoría y práctica en Europa y América” (trad. A. Gil L.) Edita IEP, Madrid, 2 vol., 1975, Vol. I, págs 388 y siguientes. Bobbio, Norberto: "La Teoría de las Formas de Gobierno en la Historia del Pensamiento Político" (trad. J.F. Fernández S) FCE, México, DF, 1987, pág. 133-137. 
Autonomías constitucionales e Instituciones Contramayoritarias

(a propósito de las aporías de la «democracia constitucional»)

Este pluralismo social, pero teñido de un cierto organicismo, también es recepcionado por la doctrina social y política de la Iglesia Católica. ${ }^{3}$ La apoteosis de las lecturas organicistas están en los fascismos, en el fascismo nacional-católico y en el corporativismo. ${ }^{4}$

Los planos referidos, Estado y sociedad civil, encuentran en la autonomía una categoría de primera importancia y con reconocimiento en la Constitución Política de la República (C.P.R.). En efecto la sociedad civil, concebida a partir de un principio de pluralismo social, se construye como un tejido de cuerpos o grupos intermedios de índole vecinal, gremial, laboral, político, profesional, civil, mercantil, entre otros, que tienen una "naturaleza" específica, es decir, fines y funciones propios, lo que conlleva la especialización y diferenciación de los cuerpos o grupos mismos (vecinales, comunitarios, gremiales, sindicales, políticos o partidos, personas jurídicas sin fines de lucro y sociedades o empresas civiles o mercantiles); fines y funciones que le imponen una natural autonomía a tales cuerpos.

La Constitución le confiere reconocimiento y amparo a los cuerpos intermedios, a través de los cuales "se estructura y organiza la sociedad" y garantiza su autonomía (artículo $1^{\circ} \mathrm{C}$. P.R.), y en consonancia con un principio de subsidiariedad, que permite un reparto de los ámbitos de lo privado y público, reconoce a las personas derechos fundamentales destinados a constituir tales cuerpos o grupos intermedios que ocupen un lugar principal en el ámbito privadopúblico y en la generación de bienes, a saber: derecho de asociación, derecho de sindicación y derecho de asociación política (artículo $19 \mathrm{~N}^{\circ} 15 \mathrm{y} \mathrm{N}^{\circ} 19$ C.P.R.); derechos fundamentales que tienen de suyo derechos implícitos, como el derecho de fundación que faculta a constituir los cuerpos como personas jurídicas a través de las figuras iuris que el ordenamiento jurídico contempla (organizaciones vecinales y comunitarias, asociaciones gremiales, centrales sindicales, federaciones, confederaciones y sindicatos; partidos políticos, corporaciones y fundaciones, sociedades civiles, sociedades mercantiles, entre otros), todo lo cual es reforzado por la libertad de contratación; poniendo especial énfasis en la dimensión negativa de los derechos, la libertad de asociación o afiliación (artículo 19 No 16 C.P.R.). La especialidad y diferenciación de los cuerpos intermedios tiene un reconocimiento explícito y mandato de prohibición en el artículo 23 de la Carta.

La autonomía en la sociedad civil y economía, acoplada al principio de subsidiariedad que permite separar el ámbito de lo privado del ámbito de lo público, son corregidas por el principio de solidaridad y el fin inmanente de bien común del Estado, que convierte al sistema de potestades (Estado- poder) en un sistema de protección social (Estado- servicios públicos),

Sánchez Agesta, Luis: “Los Principios Cristianos del Orden Político”, IEP, Madrid, 1962, en especial pág. 109140 .

$4 \quad$ Eschmann, Ernst Wilhem: "El Estado Fascista en Italia" (trad. R. Luengo T.) Edit. Labor, Barcelona, 1931. También Mihail Manoilesco: "El Siglo del Corporatismo. Doctrina del corporatismo integral y puro" (Versión de H. G. Huidobro), Santiago, 1941. 
en que las dimensiones de lo público-privado están dadas por el principio directriz de solidaridad e igualdad. Es el paso del Estado Liberal al Estado Social.

También la Constitución en armonía con las decisiones fundamentales acerca de la organización y funcionamiento del Estado, recepciona un principio de distribución funcional del poder al cual asocia una configuración nueva de los cuadros orgánicos que, en el contexto de un régimen presidencialista, le confiere centralidad al Gobierno. En el reparto de poder político (funciones y potestades) los órganos constitucionales o supremos tradicionales son titulares de las funciones clásicas (función constituyente, función legislativa, función gubernativa, función administrativa, función jurisdiccional, función jurisdiccional electoral, y función contralora), pero también se instituyen nuevos órganos receptores de funciones o subfunciones nuevas o desmembradas de funciones clásicas (función presupuestaria, función monetaria y cambiaria, función jurisdiccional constitucional, función investigativa penal, entre otras).

Para las funciones clásicas administrativas (Administración local), jurisdiccional electoral y de control (control de legalidad y de auditoría de la Administración), el Poder Constituyente utiliza las "autonomías constitucionales", a saber: Municipalidades, Justicia Electoral (Tribunal Calificador de Elecciones y Tribunales Electorales Regionales) y Contraloría General de la República, y en lo concerniente a las funciones o subfunciones nuevas el Poder Constituyente originario o derivado también utiliza las autonomías para el Banco Central, el Tribunal Constitucional y el Ministerio Público. Incluso más el Consejo Nacional de Televisión es dotado de autonomía para velar por el "correcto funcionamiento" del medio de comunicación (artículo 19 No 12 C.P.R.), encomendando su regulación a la ley de quórum calificado (Ley No 18.838).

Tal autonomía constitucional posee tres dimensiones: normativa, institucional y organizatoria, independiente de la personificación o no de tales organismos. En armonía con las "autonomías constitucionales" la Constitución en la cláusula de competencia legislativa segmentada (artículos 63 y 66 C.P.R.), le encomienda la regulación de la organización, funcionamiento y competencia de los organismos autónomos al legislador orgánico constitucional (artículos 108, 92 y 84 de la Constitución y los cuerpos legales orgánico constitucionales correlativos: Ley $\mathrm{N}^{\mathrm{o}} 18.840$, Ley $\mathrm{N}^{\mathrm{o}} 17.997$ y Ley $\mathrm{N}^{\mathrm{o}} 19.640$ ). Tales leyes orgánicas constituyen uno de los "amarres" o enclaves autoritarios perdurables del régimen autoritario una vez concluida la transición.

Con todo, quedan fuera de la técnica de las "autonomías constitucionales" el Consejo de Seguridad Nacional, y las Fuerzas Armadas, de Orden y Seguridad Pública, que más de algún autor había unido a un "poder de seguridad", ubicuo concepto del arsenal ideológico del régimen autoritario, para intentar autonomizar a la burocracia militar y policial. Ello no llegó a cuajar, y los peligros de una "pretorianización" del proceso político de la transición, se alejan definitivamente con la reforma constitucional de 2005, que reafirma el mando político-estratégico del Presidente de la República sobre tales fuerzas y el loci de éstas al interior de la Administración 
Autonomías constitucionales e Instituciones Contramayoritarias

(a propósito de las aporías de la «democracia constitucional»)

del Estado, como fuerzas dependientes del jerarca gubernamental a través de los ministerios de Defensa Nacional y de Seguridad Pública (artículo 101 C.P.R.).

\section{II.- Autonomía en la Doctrina.}

Ahora bien, corresponde abordar en este capítulo sumariamente el significado del concepto "autonomía" en lo que atañe al Estado.

La autonomía en el Derecho Público es un concepto polisémico situado en el campo de la distribución territorial del poder y de la distribución funcional de éste, y por ende, guarda relación con las definiciones específicas acerca de la forma jurídica y de la forma política del Estado. Así, en el campo de la distribución territorial del poder el concepto autonomía, de la mano del grado de descentralización, aparece diferenciado del concepto autarquía y designando sea la autonomía municipal o la autonomía política propia de estados compuestos como el Estado Regional o el Estado Federal. ${ }^{5}$

En el campo de la distribución funcional del poder la autonomía es un concepto asociado a la independencia de órganos estatales y también a la potestad de autonormación reglamentaria que tales órganos poseen. Un botón de muestra de la polisemia propia del concepto autonomía lo encontramos en la doctrina italiana ( P.Virga, G. Zanobini, Santi Romano, entre otros) ${ }^{6}$ y española.

En este contexto para Santi Romano la autonomía de los órganos del Estado se concreta en una especial relación de un ordenamiento jurídico en relación a otro, para Virga la autonomía es la potestad de un ente público para dar leyes en sentido material destinadas a formar partes del ordenamiento jurídico estatal y para Zanobini la autonomía es "la facultad que tienen algunas asociaciones de organizarse jurídicamente, de crear un derecho propio, derecho que no sólo es reconocido como tal por el Estado, sino que lo incorpora a su propio ordenamiento jurídico y lo declara obligatorio, como las demás leyes y reglamentos".

Kelsen, Hans: "Teoría General del Estado" (trad. L. Legaz) Edit. Nacional, México, 1965, págs. 214-242. De P. Virga "La regione", Roma, 1948. Asimismo de Santi Romano dos obras muy conocidas: "Fragmentos de un Diccionario Jurídico" (trad. S. Sentís Melendo y M. Ayerra Rendin) Edit. Jurídicas Europa-América, Buenos Aires, 1964, pág. 35-63 y "Principii di Diritto Costituzionale Generale”, Milán, 1947. y de G. Zanobini: "La administrazione locale", Padua, 1936 y "Curso de Derecho Administrativo" (Vol. I Parte General, trad. H. Masnatta y F. H. Picane) Edic. Arayú, Buenos Aires, 1954, págs. 165-168. Para el administrativismo italiano el distingo entre autarquía (autosuficiencia y autoadministración) propia de los entes públicos, difiere de la autonomía (facultad de los entes públicos para establecer su propia organización mediante normas con carácter de "legislación material"). Por ello para la doctrina italiana la autonomía es sentido amplio, comprende "toda potestad de dictar normas jurídicas atribuida a instituciones distintas del poder legislativo" y en un sentido restringido es la potestad normativa de entes públicos constituidos como personas jurídicas. Un matiz lo introduce Santi Romano, desde posiciones institucionistas y ordinamentalistas, para quien la autonomía es una potestad para darse un ordenamiento, la que no es privativa de entes personificados. 
En la doctrina española la autonomía esta ligada a la descentralización política, muy propia del "Estado Integral" de la II República y del "Estado de las Autonomías" actual, no así a la autarquía. (Garrido Falla). En el administrativismo español hoy se coincide en el carácter polisémico del concepto autonomía (González Navarro) y la carencia de un significado dogmático preciso (Parejo Alfonso) y su necesaria conducción a la Constitución y jurisprudencia constitucional (Santamaría Pastor).Así el concepto autonomía es empleado por la Constitución española para referirse a las Comunidades Autónomas, Municipios, Provincias y Universidades en los artículos 2, 137, y 27.10. Parejo Alfonso inspirado por Santi Romano y M.S. Giannnini sostiene como definición común de autonomía “...una cualidad de un sujeto, una organización, consistente en una cierta (derivada y limitada) capacidad de autorregularse", quedando su configuración entregada a la Constitución y ordenamiento jurídico. Con todo, el propio Parejo Alfonso utiliza del arsenal dogmático germano el concepto de garantía institucional para situar en el Estado un tipo de autonomía (local), en cuyo núcleo esencial existe una sustancia cualitativa: la capacidad política de "gestión administrativa", bajo la propia responsabilidad y a través de una organización dotada de una "doble legitimación democrática" que proporciona la representatividad (elección) y la autoadministración (participación) de los asuntos públicos locales. ${ }^{7}$

En la doctrina iuspublicística alemana contemporánea la autonomía, opera en el Estado y en la sociedad civil (Schmidt- Asmannn). En el Estado la autonomía concierne a la "forma de organización intraestatal" (Stern), que se expresa a través de la descentralización, en la que emergen entes públicos o personas jurídicas de Derecho Público que gozan de un mínimo de independencia y autodeterminación, por una parte y de legitimación democrática, por otra parte. En la sociedad civil la autonomía concierne a ciertas categorías de asociaciones de carácter profesional o económico. ${ }^{8}$

Por último, en la doctrina iuspublicística francesa contemporánea la autonomía, post reforma del Estado y de su Administración del primer septenato de Mitterrand, debe referirse

7 Garrido Falla, Fernando: “Administración Indirecta del Estado y Descentralización Funcional”, Madrid, 1950. De Luciano Parejo Alfonso son recomendables de consulta las siguientes obras: "derecho Administrativo. Instituciones generales: Bases, Fuentes, Organización y sujetos, Actividad y Control” Edit. Ariel, Barcelona, 2003, págs. 166-167; "Derecho Básico de la Administración Local”, Edit. Ariel, Barcelona, 1988, pags. 97132, y “Constitución, Municipio y Garantía Institucional” (prólogo de D. García Belaunde y edición de José F. Palomino Manchego) Edit. Grijley, Lima, 2a edición revisda y ampliada, 2000, pág. 174. De L. Parejo A., A. Jiménez Blanco y L. Ortega Alvarez "Manual de Derecho Administrativo" edit. Ariel, Barcelona, 1990. pags. 80-90. Del profesor Juan Alfonso Santamaría Pastor "Principios de Derecho Administrativo" CEURA, $1^{\text {a }}$ edic. 1990, $2^{a}$ edición, 2 vol., 1998, Vol. I., págs. 113-117. También Francisco González Navarro "Derecho Administrativo Español” Edit. EUNSA, 1ª edic., 1987, 3 vol., 2ª edición, Pamplona, 1993-1994, Vol I., págs. 346-352.

8 Schmidt - Assmarn, Eberhard: "La Teoría General del Derecho Administrativo como Sistema" (Prólogo A. López Peña y varios traductores) Edit. INAP - Marcial Pons, Madrid-Barcelona, 2003. en especial pág. 106 y ss. 
necesariamente a las colectividades locales y territoriales (Municipios, Departamentos, Regiones) y a la participación de las comunidades territoriales. Es el ocaso del prefecto napoleónico y de un Estado unitario centralista, bastante modélico durante el siglo XIX y en el cual las reformas previas a las iniciadas en 1982, no habían hecho mella sustancial. Por ende, la autonomía es esencialmente limitada y se desenvuelve en las coordenadas de la descentralización administrativa territorial, a través de colectividades locales y territoriales que gozan de libre administración de sus recursos y un ordenamiento propio, a lo que se une la personalidad moral ${ }^{9}$.

A raíz de lo expuesto acerca de la autonomía en la doctrina iuspublicística; la anotada polisemia del concepto autonomía está estrechamente ligada a la concreta y positivizada conformación jurídico-territorial y político-institucional del Estado, por lo que el estudio del concepto autonomía debe darse en el marco de las definiciones fundamentales que nuestra Constitución y ordenamiento jurídico estatal tienen, acerca de la distribución territorial y funcional del poder político contenidas en el capítulo I de "Bases de la Institucionalidad" y en la parte orgánica de la Carta Política. Lo anterior redunda en que, dada la polisemia del concepto autonomía, éste no permite hacer "tabula rasa" de la Constitución y del ordenamiento jurídico para adquirir una significación precisa.

De este modo, podemos emplear el concepto autonomía adecuadamente diferenciando las dimensiones territoriales de la autonomía (Municipalidades y en menor medida Gobiernos Regionales) designando una Administración periférica (local y regional) en el marco de un Estado unitario; y las dimensiones funcionales de la autonomía (Banco Central, Contraloría General de la República, Justicia Electoral, Ministerio Público, Consejo Nacional de Televisión, Tribunal Constitucional) que designan un principio de distribución funcional del poder.

Finalmente, el concepto autonomía en su dimensión funcional debe diferenciarse de la técnica de la personificación, es decir el reconocimiento legal de la personalidad jurídica y del patrimonio propio de entes públicos que integran el Estado o su Administración, personificación que no se agota en la figura de los servicios públicos descentralizados funcional y/o territorialmente.

A nuestro juicio, la autonomía constitucional de los órganos del Estado designan un haz de "propios poderes" de naturaleza constitucional, cuya fuente directa es la Constitución ${ }^{10}$. Tal

Luchaire, Francois - Luchaire, Ives: “Le Droit de la Décentralisation” PUF, $1^{\text {a }}$ ed 1983, $2^{\text {a }}$ edition, Paris, 1989, en especial págs. 78 y ss. También Jean Rivero y Jean Waline: "Droit Administratif” Précis Dalloz, 14ª edit., París, 1992, en especial págs. 207 - 288, 313 - 340. Del maestro René Chapus: "Droit Adminstratif Général" Montchrestien, $12^{\text {a }}$ edit., 2 vol., París, 1998, Vol I, pág. 355 - 399.

10 Ambrosini, G.:"Un tipo intermedio di Stato tra l'unitario e il federale caracterizzato dall-autonomía regionale", Rivista de Diritto Pubblico, Roma, 1933, pág. 93 y ss. 
haz de "propios poderes" importa un conjunto de funciones y atribuciones, que entrañan entre otros poderes jurídicos una potestad de autonormación, y el ejercicio de tales "poderes" con independencia en los cuadros orgánicos del Estado. Tal potestad de autonormación es de naturaleza reglamentaria (que se expresan en actos estatales típicos, a saber: autos acordados, resoluciones, acuerdos, instrucciones generales), de jerarquía infralegal e infrareglamentaria, pero situada en un campo de competencia normativa propio.

De esta suerte, los órganos constitucionales autónomos no personificados actúan con la personalidad jurídica y patrimonio del Fisco (artículo 547 del Código Civil), sin que ello pueda servir de base a una "inconstitucionalidad por omisión" como se ha sostenido en nuestro medio (Fernández). En este sentido, un botón de muestra es la jurisprudencia de la Corte de Apelaciones de Santiago, recogida en la sentencia Rol No 5901-93, de 22 de diciembre de 1993, que afirmó la falta de legitimidad pasiva del Contralor en juicio: “ $3^{\circ}$ ) Que si bien la Contraloría General de la República es un organismo autónomo, dicha autonomía es una autonomía constitucional que no implica descentralización funcional que corresponde a algunos órganos que pertenecen a la Administración del Estado. Por otra parte, carece de personalidad jurídica y patrimonio propio, sin que tampoco pueda ejercer su representación judicial el Contralor, toda vez que al especificar la Ley Orgánica Constitucional de la Contraloría sus funciones, no figura ésta" (Gaceta Jurídica No 162, diciembre de 1993, pags. 51-53). De esta manera, el Consejo de Defensa del Estado por ministerio de la ley asume la representación procesal del Fisco de Chile (artículos $3^{\circ}$ y 18 de la Ley orgánica del Consejo de Defensa del Estado), conservando la persona jurídica residual del Estado la legitimación procesal activa y pasiva.

\section{III.- Autonomía Constitucional y Autonomía Legal}

En la doctrina nacional se ha sostenido que el reconocimiento constitucional de los órganos dotados de autonomía los sitúa en el mismo nivel que los demás órganos estatales creados directamente por el Poder Constituyente, lo cual impide homologarlo a los entes públicos originados a nivel legal y menos subordinarlo, en el cumplimiento de sus funciones, a las decisiones de estos organismos, especialmente cuando se trata de los que integran la Administración del Estado, ya que esto implicaría eliminar la jerarquía y desconocer la autonomía del organismo, la que resulta decisiva para que desempeñar sus funciones constitucionales y, de esta manera, contribuir a la consecución del bien común, conforme al artículo $1^{\circ}$ inciso $4^{\circ}$ de la Carta Política. ${ }^{11}$

Ello significa que la configuración de órganos constitucionalmente autónomos, al constituir órganos de asignación especial de funciones, más allá de las tradicionales funciones o "poderes

11 Fernández, Miguel Ángel: "La Nueva Justicia Penal frente a la Constitución” Edit. Lexis Nexis, Santiago, 2006, en especial págs. 179-200. 
Autonomías constitucionales e Instituciones Contramayoritarias

(a propósito de las aporías de la «democracia constitucional»)

públicos", da lugar a un renovado diseño del viejo principio de separación de poderes o distribución funcional del poder político estatal. En palabras del administrativista Pantoja Bauzá:“... no puede dejar de llamar la atención ese conocido tema de esquiva definición que plantean esos dos grandes organismos nacionales que son la Contraloría General de la República y el Banco Central. Pese a estar consultados como organizaciones constitucionalmente autónomas, esto es, configurando lo que en derecho comparado se llamar autoridades independientes dentro del Estado, la Ley orgánica constitucional de Bases Generales de la Administración del Estado los incluyó en su artículo $1^{\circ}$ como formando parte de la Administración del Estado o Administración Pública, en un notorio esfuerzo por contraer el ámbito institucional al esquema de los tres poderes del Estado e impedir la existencia de autoridades que pudieron tener una posición legítima sin ajustarse al tradicional enfoque de un diseño estatal tripartito". ${ }^{12}$

La Constitución, directamente, de forma explícita o implícita, con mayor o menor densidad normativa iusfundamental, dota de autonomía constitucional al Consejo Nacional de Televisión, al Ministerio Público, a la Contraloría General de la República, al Banco Central; Tribunal Constitucional y a las Municipalidades, no pudiendo ser privadas de dicha nota de identidad por la ley u otra norma jurídica infraconstitucional, sin que pueda dejar de tacharse tal precepto de contrario a la Carta Política.

En un sentido análogo se pronuncia el administrativista Silva Cimma, quien al referirse a los órganos constitucionalmente autónomos, señala que: “...Se rigen por los preceptos de la Constitución Política, de la ley o leyes que los regulan y de la reglamentación interna que ellos mismos se den para los efectos de proveer a su funcionamiento. No existe relación alguna de subordinación, ni siquiera supervigilancia frente al Supremo Administrador del Estado, puesto que la índole de sus funciones, esencialmente fiscalizadoras en el caso de la Contraloría y reguladoras bancarias en el caso del Banco Central, haría inconciliable con ellas la subordinación...". ${ }^{13}$

Revisando la jurisprudencia constitucional, en fin, es posible advertir una clara evolución hacia un concepto de autonomía constitucional abierta, esto es, desde aceptar la incorporación a fortiori de los órganos constitucionales autónomos, en una concepción clásica de la división de funciones hasta concebirlos como independientes de aquéllas. Así el Tribunal Constitucional con motivo del examen de constitucionalidad del proyecto de ley orgánica constitucional de Bases Generales de la Administración del Estado, descartaba por el campo de esta ley a los

12 Pantoja Bauzá, Rolando: "Derecho Administrativo”, Ed. Jurídica de Chile, Santiago, 1996, pp. 103-104.

13 Silva Cimma, Enrique: "Derecho Administrativo Chileno y Comparado. El Servicio Público", Ed. Jurídica de Chile, Santiago, 1995, pp. 170-171; y Ferrada Bórquez, Juan Carlos, "La autonomía del Banco Central: Breve excurso acerca de su contenido jurídico”, en Gaceta Jurídica No 203, 1997, pp. 26-38. 
organismos o instituciones cuya regulación específica de que eran objeto concernía la ley orgánica, entre otros, los órganos autónomos. ${ }^{14}$ En consecuencia, cuando le correspondió controlar la constitucionalidad del proyecto de ley orgánica constitucional del Banco Central, sostuvo la Judicatura Constitucional categóricamente:

" $15^{\circ}$ Que de todo lo dicho precedentemente resulta incuestionable que al Presidente de la República le corresponde ejercer el gobierno y la administración del Estado dentro del marco que la Constitución establece y, en consecuencia, con las limitaciones que ella contempla; como asimismo, que el Banco Central por mandato de la Constitución, es un organismo autónomo, cuya composición, organización, funciones y atribuciones le corresponde determinarlas a una ley orgánica constitucional;

" $16^{\circ}$ Que lo anterior no significa, en manera alguna, privar al Presidente de la República de ejercer la administración económica de la Nación...

Y obviamente esa responsabilidad sólo tiene lugar con respecto a los actos que son propios de su administración y no respecto de aquellos actos que realice o ejecute el Banco Central, por tratarse, como se ha dicho, de un organismo autónomo y eminentemente técnico...

" $18^{\circ}$ Que ninguno, pues, de los organismos autónomos que contempla o permite la Constitución puede decirse que estén plenamente sometidos al gobierno y administración del Estado que compete al Presidente de la República. Ellos se rigen por sus propias leyes;

“ $19^{\circ}$ Que pretender que el Banco Central esté sujeto al poder jerárquico del Presidente de la República sería inconstitucional, pues la Constitución lo crea como un ente autónomo"15

Confirma esta doctrina jurisprudencial el Tribunal Constitucional al pronunciarse sobre la constitucionalidad de un proyecto de ley nonato que regulaba las "cuestiones de competencia" entre autoridades administrativas, aun antes de la reforma de 1991, respecto de las Municipalidades:

" $5^{\circ}$ Que, si bien es cierto que la Constitución en su artículo 107 no dice expresamente que las Municipalidades son entes autónomos, su autonomía se infiere del propio texto constitucional, al establecer que las Municipalidades son corporaciones de derecho público, con personalidad jurídica y patrimonio propios, y que sus atribuciones las derivan directamente de su ley orgánica constitucional. De acuerdo con la disposición mencionada es clara la autonomía constitucional de estos órganos, pues se trata de entes personificados

14 Considerandos $5^{\circ}$ y $6^{\circ}$ de la sentencia del Tribunal de 2 de octubre de 1986 (Rol N ${ }^{\circ} 39$ ). En este sentido, consultar a Cea Egaña, José Luis: "Contribución al estudio de la Ley Orgánica sobre Administración del Estado", X. Revista Chilena de Derecho No 3, Santiago, Facultad de Derecho de la Pontificia Universidad Católica de Chile, 1983, p. 645.

15 Considerandos $15^{\circ}, 16^{\circ}, 18^{\circ}$ y $19^{\circ}$ de la sentencia del tribunal Constitucional del 20 de septiembre de 1989 , Rol $\mathrm{N}^{\mathrm{o}} 78$. Este criterio ha sido confirmado en los considerandos $11^{\circ}$ a 22 de la sentencia de 30 de mayo de 1995 , Rol No 215 . 
Autonomías constitucionales e Instituciones Contramayoritarias

(a propósito de las aporías de la «democracia constitucional»)

que ha creado el Estado en el propio texto constitucional y cuyas atribuciones no las reciben del Poder Central, sino que de la ley orgánica constitucional ". ${ }^{16}$

En fin, la jurisprudencia administrativa, esta vez con posterioridad a la reforma constitucional de 1991, que dotó expresamente de autonomía a las Municipalidades (actual artículo 118), ha señalado que tal enmienda no ha hecho más que ratificar los principios ya contenidos en la Constitución y en la ley orgánica constitucional respectiva, ${ }^{17}$ aunque sin llegar a comprender todavía a cabalidad el alcance de dicha autonomía. ${ }^{18}$

Como se ha expuesto con anterioridad, la autonomía constitucional en la doctrina y jurisprudencia nacional arranca de una nueva concepción acerca del Estado, que es la distribución funcional del poder político estatal superadora del viejo principio-dogma de la separación de poderes, y que guarda relación también con el nuevo concepto de Gobierno (capítulo IV de la Constitución) en el contexto de un régimen marcadamente presidencialista.

En efecto el Gobierno es un concepto que se refiere a un conjunto de órganos vinculados con el Presidente de la República, como su jerarca máximo, a los cuales corresponde el ejercicio de las subfunciones políticas, administrativa y ejecutiva, y otras "atribuciones especiales" de naturaleza constituyente, legislativa y judicial, en la forma prescrita por la Constitución y las leyes; y que dicen relación con los roles del Presidente como Jefe de Estado, Jefe de Gobierno y Jefe de la Administración del Estado (artículos 24 y 32 C.P.R.). Tal centralidad del Gobierno guarda armonía con el techo ideológico autoritario del Constituyente de 1980 y con una estructuración del Estado compleja (Pantoja Bauzá), que sustituye la vieja división de funciones por una más coherente con el Estado contemporáneo, abandonando la división clásica tripartita y agregando nuevas funciones como la contralora, la investigativa penal, la jurisdiccional en sede constitucional, la jurisdicción en materia electoral, la monetaria, y la administrativa municipal.

En el mismo orden de ideas, la mentada autonomía constitucional tiene cabida en esta nueva concepción del Estado que da cuenta de su complejidad, y así en palabras de Cordero Vega:"La Constitución Política de 1980 estableció una nueva categoría de órganos públicos, y en consecuencia un nuevo sistema de organización administrativa. Las autonomías. Este `status' se les aplicó a los órganos de rango constitucional que ellas misma creó con esas características, como una categoría diametralmente distinta a los organismos descentralizados. Siendo así, bien puede sostenerse que son órganos autónomos para la Constitución los organismos que

Considerando $5^{\circ}$ de la sentencia del Tribunal Constitucional de 22 de septiembre de 1989 , Rol № 80.

Ley $\mathrm{N}^{\circ} 18.695$, publicada en el Diario Oficial el 31 de marzo de 1988 y sus reformas.

Dictamen $N^{\circ} 18.646$ de 1992, reproducido en Repertorio de Legislación y Jurisprudencia Chilenas. Leyes administrativas sobre Municipalidades, Santiago. Ed. Jurídica de Chile, 1994, p. 10. 
presentan especiales caracteres de independencia de frente a los poderes del Estado, hallándose sometidos sólo a la Constitución Política y a la ley que conforme a ella regula su organización, funcionamiento y atribuciones"19

\section{Por vía ejemplar es muy ilustrativo el alcance dado por el Legislador a la autonomía del Ministerio Público en su iter legis, según consta de la historia fidedigna de su creación:}

"Se entiende por autonomía la potestad para dirigirse a sí mismo, sin intervención de terceros; ella tiene una dimensión funcional consistente en el libre y expedito cumplimiento de las funciones otorgadas, y una operativa, que permite hacer cumplir las decisiones adoptadas...La autonomía en la especie está referida a los Poderes del Estado. Este concepto fue una de las claves del consenso alcanzado en el estudio del proyecto, porque es consustancial a las funciones investigadoras que se otorgan a la nueva entidad...". ${ }^{20}$

Sobre este particular Pantoja Bauzá establece las diferencias entre un órgano constitucionalmente autónomo y otro órgano al que la autonomía le ha sido conferida solamente a nivel legal, al sostener:"Dadas estas circunstancias, las autonomías constitucionales emergen a la institucionalidad con un claro designio institucional que las hace diferentes de los servicios autónomos de origen legal:

- $\quad$ Nacen de la Constitución Política de la República;

- $\quad$ Se rigen por las disposiciones en ella contenidas y por sus especiales leyes orgánicas constitucionales o de quórum calificado...

- Están al margen de los vínculos jurídico-administrativos establecidos por la doctrina clásica: Escapan a la línea jerárquica y no admiten sobre ellos facultades de supervigilancia o tutela; se autodeterminan, funcional y administrativamente, y sus directivos son autoridades inamovibles". ${ }^{21}$

Por ello, lo destaca Carmona Santander, cuando la ley califica como autónomo a un órgano estatal, significa que, integrando la Administración del Estado, se le confiere flexibilidad para que actúe:"La expresión autonomía, referida a los servicios públicos, se ha empleado en dos sentidos en el Derecho Administrativo Chileno:

- Para identificar con ella, dentro de una determinada categoría de organismos pág. 312.

Cordero Vega, Luis, “La autonomía constitucional” en la Semana Jurídica No 34, 2 al 8 de julio de 2001, p. 5. Informe de la Comisión de la Constitución, Legislación, Justicia y Reglamento del Senado, recaído en el proyecto de ley de reforma constitucional que crea el Ministerio Público, evacuado el 8 de abril de 1997, contenido en el Diario de Sesiones del Senado, sesión 39a , p. 4565.

21 Pantoja Bauza, Rolando: “La Organización Administrativa del Estado” Edit. Jurídica de Chile, Santiago, 1998, 
administrativos, a algunos que se rigen por disposiciones especiales y gozan de determinado grado de independencia de gestión, mayor del que evidencian las otras entidades de la categoría, y

- Para denominar a los servicios descentralizados, identificando así una independencia genérica de actuación-gestión frente al poder central...

Las leyes $\mathrm{N}^{\mathrm{o}} \mathrm{s} .10 .343$ y 11.764 , entonces, introdujeron el nombre y permitieron la caracterización de instituciones autónomas en la esfera del Derecho Administrativo...

Sin embargo, como se anticipara, esta terminología fue retomada por el legislador del año 1980 para referirse con ella a las instituciones fiscalizadoras.

El artículo $2^{\circ}$ del D.L. N ${ }^{\circ} 3.551$, de 1980, dispuso, en efecto, que "La Fiscalía Nacional Económica, el Servicio Nacional de Aduanas, la Dirección del Trabajo y la Superintendencia de Seguridad Social serán instituciones autónomas...y se relacionarán con el Ejecutivo a través de los Ministerios de los cuales dependen y relacionan en la actualidad...

La configuración administrativa autonómica realizada por el legislador ha ido más allá, según se dijera, puesto que las leyes orgánicas que han regido y gobiernan a las Universidades del Estado-nación también conciben a estos organismos como entidades de ese carácter...

La Ley Orgánica Constitucional de Bases Generales de la Administración del Estado no reconoce a esta categoría de entes administrativos..."

Estos organismos son parte de la Administración del Estado y es ejemplo de descentralización administrativa, como lo consigna el mismo autor al tratar las instituciones fiscalizadoras: "El hecho de que la definición legal califique -a estas entidades- de instituciones autónomas -anota Carmona Santander-, no tiene el efecto de ubicarlas en una categoría especial distinta de la de servicio público, sino sólo reforzar su independencia de gestión, sin quitarle por ello el control de tutela. En efecto, todos -sus jefes superiores de servicio- son designados por el Presidente de la República y son funcionarios de su exclusiva confianza". ${ }^{22}$

Luego, las autonomías legales de entes públicos de la Administración del Estado, son simplemente "servicios públicos legales", que generalmente son reconocidos como servicios descentralizados. ${ }^{23}$ El plus de las autonomías legales descansan orgánicamente y funcionalmente en una mayor independencia de actuación o de gestión, frente al órgano revestido de poderes de tutela o supervigilancia (de control, contable-financieros y de gestión).

En consecuencia, si bien atribuir autonomía aun órgano estatal implica siempre dotarlo de

\footnotetext{
22 Carlos Carmona Santander: "Una aproximación general sobre las Superintendencias desde la perspectiva del Derecho", marzo de 1994, trabajo inédito.

23 Pantoja Bauza, Rolando: ob. cit. Pág. 313-315.
} 
mayor flexibilidad e independencia en sus actuaciones, cuando aquel carácter es atribuido por la ley, se le asigna a un órgano que integra la Administración del Estado con todas las limitaciones que ello importa. Más, cuando aquella autonomía proviene de la Constitución, implica excluir al órgano de la Administración Pública con la serie de consecuencias que ello conlleva, entre las cuales tienen que destacarse, desde luego, que los órganos constitucionales autónomos no pueden ser fiscalizados por la Cámara de Diputados por no integrar en rigor el "Gobierno".

Finalmente, los organismos constitucionalmente autónomos son organismos "acentralizados", es decir, organizaciones públicas no dependientes del Gobierno, y que no poseen relaciones de tutela o supervigilancia, gozando de independencia jurídica, posean o no personalidad jurídica y patrimonio propio (Pantoja Bauzá).

De este modo, las autonomías constitucionales son expresión de la quiebra del viejo principio dogma de la separación de poderes, sustituido por un principio de distribución de competencias públicas, que conecta con el artículo $5^{\circ}$ inciso $1^{\circ}$ de la Constitución que residencia la soberanía "esencialmente en la nación", y su ejercicio se realiza por el pueblo y las autoridades establecidas en la Carta. "La verdadera descentralización política - dice Pantoja Bauzá- del ejercicio de la soberanía que entraña la institucionalización de esta tesis constitucional, implica establecer un nuevo diseño de construcción estatal, pues al incorporar al campo público a las autonomías constitucionales superpuso otra imagen a la tradicional de un Estado conformado sólo por servicios públicos: ahora emergen destacadamente órganos y organismos distintos de los clásicos poderes públicos, y sin embargo ejercen soberanía, ese poder supremo de determinación de un pueblo, con plena autonomía de las demás autoridades, incluso del Presidente de la República, encontrándose sometidos sólo a la Constitución y a la ley, en una dimensión del todo distinta a la que caracteriza a los servicios descentralizados, aquella gran conquista organizacional de principios de este siglo. El Estado-nación no es ya, entonces, un Estado-poder, ni un Estado de los servicios públicos, sino un Estado complejo, de composición diferenciada, que se articula democráticamente como tal al servicio de la comunidad nacional, regional, provincial y local". ${ }^{4}$ También el constitucionalista Cea Egaña señala sobre el surgimiento de las "autonomías constitucionales": "El fenómeno a que me refiero es singularmente claro y delicado, sobre todo en el proceso dinámico de modernización del EstadoGobierno, expansión de la sociedad civil y complejidad creciente que tienen los órganos que integran el aparato público. Consiste él que determinadas funciones y atribuciones, que antes no estaban confiadas por la Constitución y las leyes a determinados órganos del estado, porque tampoco habían sido descubiertas, o que se hallaban entregadas, sin mayor diferenciación, a otras instituciones del mismo, ahora, sea por virtud de los cambios constitucionales, o a raíz del

24 Pantoja Bauzá, R: "La Organización Administrativa del Estado”, ob. cit. Pág. 175-176. De José Luis Cea Egaña:”Autonomía del Banco Central", Revista de Derecho Público, Facultad de Derecho, U. de Chile, Vol. N ${ }^{\circ}$ 62, Santiago, 2000, pags. 66-79. 
carácter técnico que han adquirido determinadas medidas políticas, o en respuesta a las exigencias sociales, se encuentran radicadas expresa y excluyentemente, en estos nuevos órganos de jerarquía constitucional. Hay, en otras palabras, en virtud de la autonomía, un retiro o sustracción de potestades de ciertos órganos constitucionales, y en su reemplazo, la radicación de ellas en nuevos órganos de jerarquía constitucional que pasan a desempeñarlas, con los rasgos aludidos".

A partir del distingo entre órganos constitucionales o supremos, y dependientes o subordinados antiguo en la doctrina (Jellinek, García Pelayo) como integrantes de los cuadros orgánicos del Estado ${ }^{25}$; en nuestra doctrina Cea Egaña ha singularizado las características de este estatus o posición constitucional, a saber: "Esencialidad para la existencia del Estado Nación, aunque pueden ser sustituidos por otro; posición máxima, supremo o en el vértice superior de la organización estatal; calidad de independencia recíproca y de igualdad o paridad con los demás órganos constitucionales; control o fiscalización ejercido, como freno y contrapeso, únicamente por órganos de la misma jerarquía y jamás por otros de posición inferior; participación en el ejercicio de las funciones inherentes al Poder o Soberanía; formando la voluntad estatal y dirigiéndola al cumplimiento de los objetivos permanentes y superiores; autonomía organizativa, es decir, creación, estructura, competencia, funcionamiento y funcionamiento trazado, de manera inmediata y directa, por la propia Carta Fundamental, debiendo la ley regular tales bases, rasgos y formalidades esenciales del órgano respectivo" 26 .

Esta visión del Estado y sus cuadros orgánicos, y la autonomía constitucional es correcta, pero parcial y acrítica. Parcial en la medida que la autonomía constitucional, primero, no significa independencia completa, ni ausencia de coordinación, y segundo las funciones clásicas siguen ocupando un rol y lugar central en el Estado. Acrítica en la medida que la autonomía constitucional, primero pretende disfrazar en el carácter técnico del órgano y su composición su "apoliticidad" y sentido político-institucional, lo cual no es sino una expresión de la vieja ideología del "fin de las ideologías", y segundo no se explica la carencia de legitimidad democrática de los órganos dotados de autonomía constitucional y su difícil inserción en el Estado de Derecho y orden republicano. A nuestro juicio, el nuevo principio de distribución funcional del poder político que inserta en los cuadros orgánicos del Estado a las autonomías constitucionales, conlleva una concepción de la democracia y de la república, que admite la presencia de órganos constitucionales autónomos que operan como guardianes de un cierto orden impuesto por el Poder Constituyente originario y autoritario o por el Poder Constituyente derivado y democrático, autonomías que operan como instituciones contramayoritarias, necesarias en una “democracia constitucional”, pero alejadas de la definición de la forma política

25 Jellinek, Georg: "Teoría General del Estado “ (trad. y prólogo de Fernando de los Ríos), edit. Albatros, Buenos Aires, 1970, pags. 412- 427. También García Pelayo, Manuel: “Obras Completas” Edit. CEC, Madrid, 1991, 3 volúmenes.

26 Cea Egaña, José Luis: “Derecho Constitucional Chileno”, Edit. Universidad Católica, Santiago, 2004, pág. 4042. 
del Estado como "república democrática". Esta precaria legitimidad de las "autonomías constitucionales" obliga a limitar su poder, ya que su única legitimidad es instrumental al poder político que ejercen.

\section{IV.- Autonomía a las Instituciones Contramayoritarias.}

El reconocimiento puramente legal de autonomía a un ente público tiene una débil incidencia en la posición que el servicio público tiene en la Administración del Estado y que puede concernir a la autonomía funcional u orgánica de éste. Los ejemplos de autonomías legales de los servicios públicos de la Administración son numerosos: Servicio Electoral (Artículo 87 de la Ley $\mathrm{N}^{\circ}$ 18.556 orgánica constitucional sobre Inscripciones Electorales y Servicio Electoral), Consejo de Defensa del Estado (Artículo $1^{\circ}$ D.F.L. N 1 , M.H.,de 1993), las instituciones fiscalizadoras del D.L. N ${ }^{\circ} 3551$, de 1980, entre otros. Un elemento importante de las autonomías legales es que el Jefe superior del servicio o equivalente quede sometido en cuanto a su nombramiento o remoción y estabilidad en el empleo a un régimen de excepción de los empleos de exclusiva confianza del $\mathrm{N}^{\circ} 10^{\circ}$ del Artículo 32 de Constitución de la República, que la misma disposición admite (por ejemplo en cuanto a aquellos empleos directivos insertos en el Sistema de Alta Dirección Pública); en orden a someter el nombramiento del jerarca, previa nominación, al "derecho de confirmación” del Senado (Artículo 53 C.P.R.).

En cambio, el reconocimiento constitucional de autonomía a un ente público tiene, una fuerte incidencia en la posición que adoptaría el organismo en el Estado. La autonomía constitucional para el ente público adquiriría tanto una dimensión funcional como una dimensión orgánica. Funcionalmente designaría la independencia del ente público como órgano constitucional del Estado en los cuadros orgánicos del Estado mismo, y por ende quedar al margen de relaciones de jerarquía o tutela con el Presidente de la República, en cuanto Jefe de Gobierno y Jefe de la Administración del Estado. Orgánicamente la autonomía designaría la capacidad de administrar autárquicamente sus recursos materiales y humanos reconociendo un jerarca al interior de la organización misma. En suma el reconocimiento constitucional del ente público a éste en un "órgano acentralizado", no dependiente del Gobierno o de su Administración, independiente en el campo de sus funciones y atribuciones y además, en algunos casos, gozando de personificación, plenamente autárquico o autodeterminado en cuanto a sus recursos materiales y humanos.

Consecuencialmente la autonomía es entendida como “... la potestad o capacidad de autogobierno que, dentro del Estado tiene una organización, asociación o institución...tratase de la aptitud para regirse, en los asuntos que son de competencia de la institución pública respectiva, mediante órganos de gobierno o dirección propios, dictando normas, administrando personas y bienes, en fin aplicando sus recursos al cumplimiento de las finalidades que le han sido confiados por la Constitución y las leyes" (Cea Egaña). Natural conclusión de esta definición, aunque controvertible, es sustraer a las "autonomías constitucionales" de la 
Autonomías constitucionales e Instituciones Contramayoritarias

(a propósito de las aporías de la «democracia constitucional»)

Administración del Estado y de la orbita del control político confiado a la Cámara de Diputados.

A nuestro juicio, "autonomías constitucionales" como Contraloría General de la República, Banco Central y Municipios, integrados a la definición que el Legislador enuncia de la Administración del Estado (artículo $1^{\circ}$ de la Ley $\mathrm{N}^{\circ} 18.575$ orgánica constitucional de Bases Generales de la Administración del Estado), no dejan de integrar tal Administración merced su autonomía de fuente constitucional, sino que poseen un estatuto legal orgánico constitucional específico y se localizan funcional y orgánicamente en la Administración, pero gozando en el campo de la asignación de funciones correspondiente, de "propios poderes" de gobierno y dirección (autonomía-independencia), y de autonormación reglamentaria. Asimismo, el control político o "potestad fiscalizadora" de la Cámara de Diputados (artículo 52 No 1 C.P.R.) concierne a los "actos del Gobierno", lo que comprende bajo la contracción "del”, a los actos de Gobierno o políticos y a los actos de la Administración, es decir, a la actividad decisional de los cuadros orgánicos del Estado situados en el "Gobierno", y en el "Gobierno y Administración Interior del Estado" (capítulo IV y XIV C.P.R.), pero que por sus instrumentos de control (acuerdos y oficios fiscalizadores, interpelaciones y comisiones investigadoras) exigen que el Presidente de la República en cuanto jefe de Gobierno y jefe de la Administración del Estado o sus ministros, estén revestidos de poderes de jerarquía o tutela respecto de los órganos cuya actividad es fiscalizable; lo que obviamente no se da tratándose de las "autonomías constitucionales" que integran la Administración.

En cambio, la obligación de proporcionar informes y antecedentes a las Cámaras y órganos internos (v.gr. Oficina de Informaciones) del Congreso Nacional por los organismos de la Administración del Estado establecida en el artículo $9^{\circ}$ de la Ley $\mathrm{N}^{\circ} 18.918$ orgánica constitucional del rubro, sí empece a las "autonomías constitucionales"; lo que es confirmado por la jurisprudencia administrativa de la Contraloría General de la República (Dictámenes $27729 / 1991,28091 / 1992$ y 27951/1993). En efecto, tanto el artículo $1^{\circ}$ de la Ley $\mathrm{N}^{\mathrm{o}} 18.575$ como el artículo $9^{\circ}$ de la Ley $\mathrm{N}^{\circ} 18.918$ emplean un concepto amplio de Administración del Estado (en armonía con la historia fidedigna de los preceptos), la obligación de proporcionar informes y antecedentes guarda directa relación con la función inspectiva y de control político asignada a la Cámara Baja al menos, todo lo cual es reforzado con el reconocimiento del principio de publicidad de los actos y resoluciones de los órganos del Estado, y la excepcionalidad de la reserva o secreto, la que es sometida al dominio segmentado del legislador de quórum calificado en el nuevo artículo $8^{\circ}$ de la Constitución, adicionado por la reforma constitucional de 2005, promulgada mediante Ley $\mathrm{N}^{\mathrm{o}} 20.050$.

Un buen ejemplo de las implicancias que el reconocimiento de autonomía constitucional, así como del reforzamiento del principio de jerarquía al interior de la organización, lo tenemos con lo que se ha expuesto acerca del Ministerio Público. En particular la Comisión de Constitución, Legislación y Justicia de la Cámara de Diputados, al cumplir la reforma su segundo trámite constitucional precisó el significado de la autonomía en los términos que se reproducen: 
"Se dijo que la autonomía le permitirá dirigirse a sí mismo sin intervención de terceros. Y que ella tiene una dimensión funcional, consistente en el libre y expedito cumplimiento de las funciones otorgadas, y una operativa que permite hacer cumplir las decisiones adoptadas. Siendo su contrapartida los mecanismos de control y la responsabilidad de los fiscales. La autonomía, se precisó, está referida a los poderes del Estado. Observándose que este concepto fue una de las claves del consenso alcanzado en el estudio del proyecto, porque es consustancial a las funciones investigadoras que se otorgan a la nueva entidad. Por esta razón y por que no cumple un cometido jurisdiccional, el Ministerio Público queda excluido del control de la Corte Suprema. Si la autonomía hace referencia a la libertad de acción respecto del entorno social y político en que se inserta el organismo, la independencia, se digo, mira hacia dentro del mismo, a la libertad de los fiscales, a fin de que no se trasformen en meros subordinados de quienes detentan cargos superiores. El concepto de jerarquía, se puntualizó, supone asimilar al Ministerio Público a la estructura corriente de las entidades que conforman el Estado chileno. Alude al hecho de que el Fiscal Nacional podrá dar instrucciones generales, fijar prioridades e indicar en forma genérica modos de actuar, para el ejercicio de las funciones y para la operación del organismo, y que los fiscales regionales, por su parte, podrán dar lineamientos para impulsar las investigaciones y para el ejercicio de la acción penal pública, con la finalidad de que estas funciones se cumplan efectiva y eficazmente en sus respectivas áreas geográficas. Lo anterior no excluye, por cierto, las funciones administrativas propias de cualquier organización." ${ }^{27}$ En un sentido análogo, como se citó anteriormente la Comisión de Constitución Legislación y Justicia del Senado se pronunció acerca del concepto autonomía.

Más lejanamente, en la etapa de génesis de la Constitución vigente, el Banco Central es concebido por el Poder Constituyente de época como "instancia técnica e independiente" destinada a procurar la emisión monetaria y en coordinación con el Gobierno en la conducción económica del país, todo en el marco de un Orden Público Económico (Anteproyecto Constitucional y sus Fundamentos, Editorial Jurídica de Chile). Congruente con ello el Mensaje que da origen a la Ley orgánica constitucional del Banco Central al referirse a la autonomía y sus fines señala que con ello “.....además de preservar su carácter técnico, darle el nivel necesario para cautelar ciertos valores económicos fundamentales, a saber, la estabilidad de la moneda y del sistema financiero y el normal desenvolvimiento del comercio exterior y las operaciones de cambios internacionales...". En consecuencia, se ha sostenido en nuestro medio que un Banco Central autónomo es pieza esencial del Orden Público Económico, de la garantía de libertades económicas y del principio de subsidiariedad (Cea Egaña); es decir, de un "orden económico y social"de talante neoliberal ${ }^{28}$.

\footnotetext{
27 Emilio Pfeffer U.: "Ministerio Público. Antecedentes de la Reforma Constitucional”. Edit. Jurídica Conosur, Santiago, 1997. pág. 58-59. Idem en "Historia de la Ley № 2, creación del Ministerio Público, Cámara de Diputados, 172-173.

28 Cea Egaña, José Luis: “Autonomía...” ob. cit., págs. 67-68. Idem Fermandois, Arturo: “Derecho Constitucional Económico” Ediciones Universidad Católica de Chile, 2a edición, Santiago, 2006, págs. 63-69.
} 
Autonomías constitucionales e Instituciones Contramayoritarias

(a propósito de las aporías de la «democracia constitucional»)

También el Tribunal Constitucional es concebido como organismo autónomo por el Poder Constituyente de época, y a modo ilustración se afirmó en el seno de Comisión de Estudios de la Nueva Constitución por la comisionada señora Bulnes que esta Judicatura no era : “...una desmembración del Poder Judicial, sino más bien un órgano de carácter netamente técnico, y añade que al dárseles una mayoría muy evidente a los miembros de la Corte Suprema aparece un tanto confundida la función judicial con la de dicho Tribunal, lo que no otorga buena imagen ni es conveniente, pues muchas veces ese organismo resolverá materias de naturaleza política" (sesión 359).

En consecuencia, la autonomía constitucional de los órganos del Estado está asociada también a un tipo de legitimidad no democrática sino estrictamente constitucional, por lo que sus "propios poderes" conciernen a una competencia tasada y a una fuerte sujeción a la Constitución y a la ley, usualmente de tipo orgánico constitucional. Por ello en el nombramiento del jerarca de los organismos dotados de autonomía constitucional intervienen los órganos constitucionales supremos del Estado, a saber: en el nombramiento del Fiscal Nacional intervienen la Corte Suprema como cabeza de Poder Judicial, el Presidente de la República y el Senado; en el nombramiento de los miembros del Consejo del Banco Central intervienen el Presidente de la República y el Senado, en el nombramiento del Contralor General de la República intervienen el Presidente de la República y el Senado, en el nombramiento de los consejeros del Consejo Nacional de Televisión intervienen el Presidente de la República y el Senado, y en el nombramiento de los ministros que integran el Tribunal Constitucional intervienen el Presidente de la República, el Congreso Nacional y la Corte Suprema.

La intervención de los órganos supremos del Estado en el nombramiento de los jerarcas singularizados, sean órganos unipersonales o colegiados, intervienen los "poderes públicos" tradicionales para morigerar la falta de legitimidad democrática de estos órganos, y asegurar un equilibrio político institucional en las lógicas de mayoría y de minoría, lo que es particularmente evidente tratándose del "derecho de confirmación” general y especial del Senado (artículo $53 \mathrm{~N}^{\circ} 5^{\circ}$ y $9^{\circ}$ C.P.R.).

Persiste tratándose de las "autonomías constitucionales", en especial del Banco Central y del Tribunal Constitucional, un déficit en materia de sistema de controles y responsabilidades; aporía de la "democracia constitucional" que está en contradicción con las definiciones acerca de la forma política y forma jurídico política del Estado.

\section{VI.- Conclusiones}

Las "autonomías constitucionales" tienen como telón de fondo la "democracia constitucional", diseñada para hacer frente al mentado peligro de la "tiranía de las mayorías", de modo que los principios de mayoría y de minoría y sus reglas supone abrir espacios institucionales a la representación y a la deliberación pública, y también abrir espacios a los 
centinelas o guardianes de la Constitución, como precipitado normativo iusfundamental del pacto que fija las reglas preliminares y del juego del sistema político. Esta "democracia constitucional" se presenta a sí misma como una "democracia deliberativa" poniendo énfasis en la racionalidad procedimental de las decisiones políticas, pero olvida muchas veces a los centinelas o guardianes del orden fundamental que hace posible la deliberación. El quid está en que en los “...procesos deliberativos deben poder manifestarse las diversas opiniones en atención a la diferente adscripción política de aquellos que las mantienen, de tal modo que el principio más elemental en cuanto a la esencia del debate no es la mayoría, sino el de pluralismo y, por tanto, el de minoría" (Requejo).

Ahora bien en cuanto a los temas abordados en este trabajo es menester precisar que las "autonomías constitucionales" y legales son técnicas diversas, la primera incide en el locus del órgano constitucional en los cuadros orgánicos del Estado y tiene dimensiones normativas, institucional y organizatoria, de modo tal que puede ejercer funcional y orgánicamente con independencia sus "propios poderes", y la segunda incide en un plus de autonomía de servicios públicos descentralizados situados en la Administración del Estado.

De esta suerte, las “autonomías constitucionales" son una técnica que permite en el Estado contemporáneo el alojamiento de instituciones contramayoritarias en armonía con la "democracia constitucional". Esto se produce por la vía de emplear a la Constitución como principio-fuente de legitimidad del poder del Estado, designando el tránsito de la soberanía popular a la soberanía de la Constitución, con lo cual la Carta Política en cuanto a fuente de reparto de poderes le asigna a ciertos organismos autónomos funciones de especial relevancia, que consisten en la guarda o custodia de un cierto orden político- institucional (legalidad o constitucionalidad) o un cierto orden socioeconómico. Con ello la propia Constitución está autoafirmando sus principios de constitucionalidad: supremacía formal y material, valor normativo y eficacia normativa. Esta "democracia constitucional" es una síntesis de los principios de mayoría y de minoría, como reglas de adopción de decisiones políticas, en la que la garantía final de respeto de tales reglas, constitutivas de un orden fundamental político, social y económico, está en la Constitución estatal. Ello importa instalar en el cuadro orgánico básico del Estado y en la carta de derechos a las instituciones contramayoritarias, paradójicamente como remedio a la "tiranía de las mayorías"; generando demasiadas veces una "tiranía de los valores" de los centinelas del orden fundamental (político-institucional o socioeconómico).

De este modo, la Constitución identifica específicas instituciones contramayoritarias constituidas como "autonomías constitucionales" como verbigratia el Tribunal Constitucional o el Banco Central, concebidos como centinelas o custodios de un orden constitucional o un orden económico- social, centinelas que en rigor son una "aristocracia togada" o "tecnocracia" según el caso, en quienes se deposita la custodia de un orden, con profundas raíces ideológicas. Tal orden constitucional y orden económico-social tienen su fuente de creación institucional en la Constitución de 1980, otorgada, autoritaria y neoliberal. 
Autonomías constitucionales e Instituciones Contramayoritarias

(a propósito de las aporías de la «democracia constitucional»)

El Poder Constituyente derivado democrático, que finalmente merced la reforma constitucional de 2005, promulgada mediante Ley N 20.050, suprime los "enclaves autoritarios", conserva en la Constitución la herencia perdurable del régimen anterior sus instituciones contramayoritarias como centinelas o custodios de un orden constitucional que todavía carga parcialmente con la herencia autoritaria o de un orden socio económico (Constitución Social y Constitución Económica) que carga casi totalmente con la herencia autoritaria y neoliberal. Tales centinelas o custodios son una aristocracia otorgada o tecnócratas que adoptan decisiones públicas, al margen del proceso de deliberación pública, imponiendo sus visiones ideológicas acerca del orden que están llamados a conservar. Tales instituciones contramayoritarias tienen como función reequilibrar el poder político atribuido a las funciones tradicionales y sus órganos supremos como Gobierno y Congreso Nacional, como ocurre con el Banco Central en el campo de la política monetaria, cambiaria y crediticia con la dirección gubernamental de la política económica o con el Tribunal Constitucional en el campo de la inconstitucionalidad de normas con los poderes normativos legislativos y reglamentarios.

En suma, la contemporánea "democracia constitucional" que desea hacer frente a la "tiranía de las mayorías", introduciendo instituciones contramayoritarias que cautelen la separación de poderes y el carácter limitado del poder, paradójicamente enfrenta el peligro de la "tiranía de los valores", que imponen la aristocracia togada o los tecnócratas, desde la fortaleza normativa, institucional y organizatoria que les confiere la autonomía. Ciertamente tales instituciones contramayoritarias son necesarias como ocurre con el Tribunal Constitucional, ya que como bien afirma la jurista de la Escuela de Oviedo Paloma Requejo , tal jurisdicción “... juega un papel principal en la realización del ideal de equilibrio constante entre los grupos mayoritarios y minoritarios, pues, al controlar la constitucionalidad de las normas, protege eficazmente a las minorías frente al avasallamiento del dominio de la mayoría parlamentaria"29.

Lo anterior nos invita a admitir, sin filias o fobias, la necesidad de las instituciones contramayoritarias y de la técnica de las autonomías constitucionales, necesidad acicateada por la guarda de la Constitución como pacto político de una sociedad pluralista y fundadora de una "democracia constitucional", reconociendo el foco de problemas que se abre a propósito de la necesidad de estas instituciones, dado el déficit de legitimidad que posee la Constitución vigente, que nace como Constitución otorgada, autoritaria y neoliberal.

Al mismo tiempo, no debemos renunciar en el plano teórico-práctico a los espacios propios que tiene la política y la ciudadanía en una "democracia constitucional", y en particular no

29 Requejo Rodríguez, Paloma: "Democracia parlamentaria y principio minotario. La protección constitucional de las minorías parlamentarias”. Edit. Ariel, Barcelona, 2000, páginas 28-29, 135. También se puede consultar al ambicioso libro de V. Ferreres Comella: "Justicia constitucional y democracia” Edit. CEPC, Madrid, 1997, en especial págs. 275 y siguientes. 
debemos renunciar a la soberanía popular (denominada impropiamente "soberanía borrosa" o "soberanía de la Constitución") como principio legitimista del poder político estatal.

A la luz de la reivindicación del principio democrático en la construcción del Estado, se hace imperioso reforzar el control social, político y jurídico de tales instituciones y de sus centinelas, y además, el régimen de responsabilidades a que están sometidos.

La adopción de un sistema de controles y responsabilidades coherente para las instituciones contramayoritarias, constituidas como "autonomías constitucionales" es un imperativo de Constitutione y lege ferenda en un orden político republicano y democrático.

En conclusión, la quiebra del viejo principio de separación de poderes y el surgimiento de instituciones contramayoritarias, no puede importar el sacrificio del Estado de Derecho y de la República Democrática como decisiones fundamentales acerca de la organización y funcionamiento del Estado. Esto significa que el poder atribuido a las instituciones contramayoritarias configuradas como autonomías constitucionales en especial, debe estar sometido a controles y responsabilidades coherentes y además, debe configurarse como una competencia tasada en la Constitución y la ley, por lo que sus funciones y atribuciones se agotan en el ejercicio independiente de sus "propios poderes" consistente en la actualización mediante decisiones "técnicas" u objetivas-objetivables (sentencias, autos, acuerdos, dictámenes, resoluciones ) del ordenamiento jurídico. Asimismo el reclutamiento de los miembros (centinelas o guardianes) de las instituciones contramayoritarias, más allá de los méritos, debe ser reflejo de un amplio pluralismo político, social e ideológico, de suerte que sus decisiones sean resultado de un diálogo abierto y público, a lo menos en cuanto a las decisiones y sus fundamentos. En suma, como hemos sostenido en otros lugares, parte importante de la legitimidad de ejercicio de estas instituciones contramayoritarias estriba en el despliegue efectivo de su competencia y en los fundamentos de sus decisiones. 